\title{
Authorship Methodology, Rational Thinking and Modernity in Abu Alqasem Al-Zajajee's Book Aleedah Fi Elal Alnahu-Clarifications in Syntax Justifications
}

\author{
Ahmad H. Al Nuaimi ${ }^{1} \&$ Hanna Y. Abu-Jaber ${ }^{1}$ \\ ${ }^{1}$ Department of Humanities, Faculty of Engineering Technology, Al-Balqa' Applied University, Amman, Jordan \\ Correspondence: Hanna Y. Abu-Jaber, Department of Humanities, Faculty of Engineering Technology, \\ Al-Balqa’ Applied University, P. O. Box 15008, Amman 11134, Jordan. E-mail: hannaabujaber@hotmail.com
}

Received: November 5, 2014 Accepted: November 28, 2014 Online Published: January 27, 2015

doi:10.5539/ijel.v5n1p175 URL: http://dx.doi.org/10.5539/ijel.v5n1p175

\begin{abstract}
This is a study of Abu Alqasem Al-Zajajee's book Clarifications in Syntax Justifications in order to create authorship methodology and style for the writer by presenting the book content as a model for rational thinking and modernity in the fourth century of Muslim calendar. This study shows that modernism is not attributed to a specific period of history or monopolized commodity for science or a figurative manifestation of creativity; nevertheless, it is a methodology in authorization and thinking based on being free of tradition and committing to your vision-visibility.

This study shows that Al-Zajajee had created new writing techniques like using self-analysis, rational thinking, reasoning and providing philosophical evidences. He divided his book into two chapters; the first chapter talks about headlines of clarification, the second chapter about controversial issues, without committing himself to a certain size for the headlines or the issues; therefore, the same headlines were discussed in several lines while some issues in one and a half line.

Consequently, this study had presented recognition card for Al-Zajajee providing deep critiques for the contents leading to a clarified and specified results within its own borders.
\end{abstract}

Keywords: Al-Zajajee, old Arab authors, fourth century of Muslim calendar, Aleedah Fi Elal Alnahu—Clarifications in Syntax Justifications

\section{Introduction}

Modernism is not limited to a certain time, or for a certain nationality. Thus, Ibn Qotaibah said "I had seen some scholars who liked silly poetry just because it's said before and attacked sophisticated poetry. Poetry is not meant to be for a certain nationality or time but it has been divided between all human beings making every old poetic gift as the new" (Al-Dainoori, 1985, p. 19).

Thus, what is called modernism today will not stand on the borders of our time since a lot of scholars will study it and reach conclusions related to it because it is destiny that this work be criticized by the coming generations to study us. To sum up, post-modernism -restricted to this study- is not but illusions without evidences based on reality. These illusions come because literature is accumulative experience from generation to generation realizing that every new experience will be determined by the coming generations from their literature and science, so we can't say post post-modernism for the next coming generation and post, post, post modernism... and so on?

While reading this book Clarifications in Syntax Justifications for Abu Alqasem Al-Zajajee who died in 340 in Muslim calendar, we have noticed that the book is rich in its style, the way it is presented but the most important is the attitude of the writer to be different in his objectives and visionary outlook; this variation in roots presents new techniques in argumentative ability of reasoning.

This study has chosen some cases related to the writer and his generation to deal with the book in an easy manner - the content of the book - through style and details. Moreover, this study shows the $4^{\text {th }}$ century in Muslim calendar had certain characteristics that affected the book style like creativity due to intervention between critic, linguistics and literature in the matter of breaking old style and creating their own voice. 
Furthermore, Dr. Mazen Al-Mubarak, the interpreter of the book, added all Al-Zajajee's remaining issues which made the book attractive.

Therefore, he wrote Al-Zajajee biography as a second book and Syntax Reasoning, Origins and Developments as a third book.

This study tried hard to benefit from Dr. Al-Mubarak without repeating his style by choosing subjects from the book sections avoiding unnecessary repetition or opening a new details in syntax that need a lot of researches.

\section{Al-Zajajee: Birth, Life and Death}

$\mathrm{He}$ is Abu Al-Qasim Abd Al-Rahman Ibn Ishak, nothing mentioned after that although a number of translators had translated for him (Al-Mubarak, 1984, p. 7). He was born in Nahwand - south of Hamadan-visited a lot of countries through his life like Baghdad and met his teacher Ibrahim Ibn Al-Sori "Al-Zjaj" and stayed next to him until people named him "Al-Zajajee" after his teacher. Then, he travelled to Al-Sham residing Halab, after that to Damascus where he lectured and worked (Al-Zajajee, 1959, p. 1).

Moreover, the historian, Ibn Khalekan had said about him: "He is Baghdadi in origin and early life, Nahawndian in family roots and birth (Al-Mubarak, 1984, p. 7).

He was raised as a lover for studying taking a place in the classes of scholars and philosophers. He was taught by twenty teachers as if he was trying to collect his generation culture since his trails to be a student to every well-known teacher even though some had contradictory ideas and followed different schools (Al-Mubarak, 1984, p. 7).

We find in Clarification Book that Al-Zajajee mentioned a number of teachers, scholars and philosophers he met like Abu Ishak Al-Zojaj, Abu Jafar Mohammad Ibn Rostem Al-Tabaree, Golam Ibn Othman Al-Mazani, Abu Al-Hasan Ibn Kisan, Abu Baker Ahmad Ibn Al-Hussein Ibn Abbas, who was famous for Ibn Al-Khiat, Abu Baker Ibn Al-Srag, Abu Al-Hasan, and Ali Ibn Suleiman Al-Akhfash.

Moreover, he mentioned some teachers from Al-Kofa school he was influenced by like Abu Al-Hasan Ibn Kisan, Abu Baker Ibn Shokeer, Abu Baker Ibn Al-Khiat because those were ideal teachers in Al-Kofa School due to their knowledge on the references of Al-Basra school, too (Al-Zajajee, 1959, p. 78-79).

A fact that Al-Zajajee liked Al-Basra school is his speech, that he had taken also from Al-Kofa school, which meant to be a secondary knowledge. Realizing that this speech wouldn't put Al-Zajajee on a stage of not being objective, he also tried to study Al-Kofa human-studies and made a loud voice of comparison based on science of reasoning, mental argument and logical assessment.

At last, his death date is controversial because Abu Baker Al-Zobaidee said it was 337 in Islamic calendar. Ibn Tazzi said it was in 339 while Ibn Al-Athear, Jazem Al-Katfai, Ibn Alameel Al-Hanbalee, Ibn Shaker Al-Katabee and Al-Yamenee said it was in 340, as Ibn Asaker agrees (Al-Mubarak, 1984, p. 8).

\section{His Education (Cultural Roots)}

Muslims had realized that the message of Islam is a civilized message in the first rank, so they translated the culture of other nations, their literature and philosophy, especially the works of Plato and Aristotle. This issue was emphasized in many old Arabic books that talked about both philosophers. Therefore, Al-Zajajee was one of those who had reconstructed his culture through this deep civilized vision which means that his education exceeded the Arabic culture ranges to reach Greek philosophers and scholars, too.

Definitely, Al-Zajajee had mentioned Plato and Aristotle by names while talking about the disagreement in the definition of philosophy due to Plato's opinion that philosophy is to subdue the bodily appetites (Al-Zajajee, 1959, p. 47). Then he added that others said "philosophy is to follow the creator upon the created power; adding that Aristotle said that philosophy is to form the essence of anything especially science (Al-Zajajee, 1959, p. 47).

Consequently, Al-Zajajee had gathered a lot of nations cultures because he knew that the real scholar can't be effective unless he had a deep vision, open-minded and sophisticated enough to add new concepts to human knowledge.

Al-Zajajee's cultural background was distinguished because he had lived at the end of the third century and the beginning of fourth century when Islamic culture reached the peak in maturity and modernity. He lived at the time of Al-Akhfash, Ali Ibn Soliman, Al-Zjaj, Ibn Al-Sarraj, Ibn Al-Anbari, Al-Seerafee, Ibn Doriad and others. He was one of the best but the most active in having education and authorship (Al-Zajajee, 1959, p. 13). 


\section{His Books}

Most of the researches and scholars said that he had composed a lot of books. Some of these books hadn't reached us. In this study we would like to thank Mazen Al-Mubarak and Abd Al-Hussein Al-Mubarak for their effort in dealing with the new review for Al-Zajajee book. The Clarification: Another book about Al-Zajajee's life by Al-Mubarak is Al-Zajajee; Life, Books and Syntax School, whereas Dr. Abd Al-Hussein had revised the book which was named The News of Abu Al-Quasem Al-Zajajee in a new version called Al-Amalee which was revised by Dr.Abd Al-Salaam Haroun since Dr. Abd Al-Hussein had found a transcript titled The News of Abu Al-Quasem Al-Zajajee, which he later re-authorized it in spite of the similarity in vision, and subjects with Al-Amalee. Some argued that "Abd Al-Hussein Al-Mubarak point of view about the different two titles for the same book was due to copiers and not Al-Zajajee wish. Thus, they were able to put two titles for the same book. Our view is based on historians, biographers and the stratum books. All the previous books haven't any notion that there is a book named The New of Al-Zajajee in spite of the manuscript mentioning of Al-Zajajee in its first drawing" (Al-Zajajee, 1980, p. 11).

Consequently, the Arabian resources had agreed that Al-Zajajee had written the following books:

1) The Sentences or Al-Jomal which is a book of syntax, recopied and reorganized by faculty of Arts in Algeria.

2) The Clarifications in Syntax Justifications recopied and recognized by Mazen Al-Mubarak in 1959 in Cairo by Dar Al-Oroba.

3) Description of the Preface of the Writer Literary this is a book of description for Ibn Kotaibah speech about the literature of any writer exposing us to variety of examples full of language, syntax and morphology. The manuscript of this book is found in the house of Egyptian books under No 39 in literature and another copy is found in Istanbul. Moreover, there are two copies in the Faculty of Manuscripts in Istanbul.

4) Al-Zaher Summary under No 557 language in the House of Egyptian Books as a hand written version.

5) "Allah Names, Attributive derived names from the Holy Quran concerning language, resources and interpretation this manuscript is also found in House of Egyptian Books under No 3 language.

6) Substitution, Castigation and Analogue with a hand-written copy in the Faculty of Manuscripts in Istanbul under No 356 syntax.

7) Al-Lamat a book is found in Faculty of Manuscripts in Istanbul under No 792.

8) The Invention of Rhythms which was mentioned by Al-Siawtee, and also mentioned in the book Revealing of Doubts, also mentioned in Ibn Al-Nadeem index and the famous essence books of history.

9) The Satire mentioned only by Al-Zajajee himself in his book The Camel.

10) The Combined of Poetry Kinds and Rhythms which was mentioned by Ibn Khair Al-Ashbeelee.

11) The Meaning of Alphabets is a book which was attributed to Al-Zajajee just by Ibn Khair Al-Ashbeelee, and then the orientalist Broklman put it as one of Al-Zajajee books in another name called The Meanings of Letters.

12) Sibawaih Message Description which was also mentioned in Al-Zajajee book The Clarifications in Syntax.

13) The Description for Alalat and Al-Lam for Mazani which was mentioned in another three books; The Objective of Preachers, The Revealing of Secrets and The Essences of History Tales.

14) The News of Abu Quasem Al-Zajajee which was revised and re-written by Abd Al-Hussein Al-Mubarak. It was edited by the Ministry of Media and Culture in Iraq in 1980. This book was previously revised and re-written under another name Al-Amadi (Al-Zajajee, 1959, p. 8).

\section{Between Syntactic Function and Reasoning}

If we can define the syntactic function as "to impose for the end of the word in a special kind of prose" (Al-Ru'aid, 1987, p. 320), we will also find two definitions for this function weather in use or in meaning. For example, the word in use "did" can be derived into doing or doer and in use "it is the change at the end of the word in diacritic marks (Ibn Manthour, 1991, p. 476).

On the other hand, the syntactic reasoning has a relation to argumentative school to explore the root of the thing. Moreover, the reasoning for philosophers is determined by what the word will be by changing the context in different examples like cause and effect, subject and verb, materialistic or portrayed, or intentional (Anees, 1972, p. 632). 
Consequently, the syntactic function has a deep relation with sentence analysis and what is the spelling of the suffix of the word contextually (Al-Aqtash, 2011, p. 8) which includes philosophical, intellectual and logical dimensions for reasoning syntactically and that will enable the study to declare that syntactical reason has widen the horizontal for parse movement establishing a wider school to judge syntactically controversial issues. These conversations paved the way to a lot of reasoning books in the $4^{\text {th }}$ century in Muslim calendar but a minority had stayed until now like: The Book of Syntax Reasons; The Book of Denying Syntax which were written by Al-Hasan Ibn Abdullah, who was famous in Lakdah from Isfahan; Haroun Al-Hayak's book of reasoning in syntax; the chosen essays for Mohammad Ibn Ahmad Ibn Kisan; The Clarification Book in the Reasoning by Mohammad Ibn Ali Al-Askaree; Problems in Syntax for Al-Hasan Mohammad Ibn Abdullah known as Ibn Al-Warak; Description of Syntax Reasoning for Abu Al-Abbas Ahmad Ibn Mohammad Al-Molhabee; Syntactic Language Functions Book by Said Ibn Saad Al-Pharokee (Al-Mubarak, 1974, p. 94).

Generally speaking, if the solecism was the first inspiring motive for language gathering and documenting deriving and classifying rules for Arabic syntax (Al-Afghani, 1957, p. 6), and if the most important move to resist solecism by destroying it on the hand of Abu Al-Soud student (Makram, 2012, p. 62), this research will bring a new phase added to the previous phases of the efforts which leave no doubts that Arabic is a living language for a living civilization. This context in the study will remind us by a famous quotation for Abd Al-Qaher Al-Jerjanee: "if you have doubts, look them out" (Al-Jarjani, 1988, p. 37).

\section{6. "Clarifications" Sections and Problems}

Al-Zajajee had mentioned two subjects of the book under two names: the first is "sections", the second is "different problems", and he didn't mention chapters but only time while discussing "different syntactic problems" when he mentioned a problem under the title "a chapter of Al-Zajajee comments: commentary about the addition of time adverbial to tenses". His book has twenty three sections, several syntactic problems about twelve problems besides putting an introduction to introduce the outcomes and the analysis of what was mentioned with writing.

\section{The Approved Copy}

The copy that Mazen Al-Mubarak had written in one hundred fifty pages is the reliable copy for our study. It consists of a word of trust from Mahmoud Mohammad Shaker, the preface by Shawkee Daif and another forward by Mazen Al-Mubarak. It tells us about the book and his author describing the copy in details by explaining his vision through re-authorization of old book contents.

\section{Al-Zajajee Introduction for Clarification}

Al-Zajajee started his introduction by the defining of the book, the reasons for writing it, and his style of writing. Starting with the definition: it is a book dealing with syntax problems by negotiating, mentioning secrets, discovering the clears and mysterious without looking at the origins because a lot of classified books of origin are there (Al-Zajajee, 1959, p. 38). Secondly speaking, Al-Zajajee was inspired to write this book "to be a unique book in reasoning of syntax and understanding syntax fully" (Al-Zajajee, 1959, p. 38).

Moreover, Al-Zajajee explained - depending on a methodology — that he wrote it without prejudices in a summarized way "forced by analogy presenting two points of view without prejudices" (Al-Zajajee, 1959, p. 39). Thus, he made this book chosen, polite, bridged, little stories, variations, techniques and presenting the speakers (Al-Zajajee, 1959, p. 39). At the end of the introduction he divided the book into two sections, the first by presenting syntactic reason, and the second by presenting abstracted questions (Al-Zajajee, 1959, p. 40).

\section{The First Part: The Sections of Clarifications}

Al-Zajajee emphasized that speech can be divided into: noun, verb and a letter. Then he challenged other scholars to find a fourth part or more to stand against Sibawih speech and asked them to have the evidence or the clue "because doubts can't go over facts" (Al-Zajajee, 1959, p. 41).

\section{What Can Be Said About Linguistic Dissimilarity in Specifying Noun, Verb or a Letter?}

Al-Zajajee said that dissimilarity is humanly-accepted habit and couldn't be astonished because philosophers had different opinions in specifying philosophy itself. Some said its learning wisdom while others said it's natural knowledge for all the collective things. Nevertheless, some said that philosophy is to know the things on the basis of divinity, realizing it mentally, and distinguishing it humanly by realizing it by senses. On the other hand, some said that philosophy is facing death by killing lusts as it was said by Plato. Moreover, some philosophers agreed that philosophy is to follow the creator's orders realizing limits of the created. 
Consequently, Aristotle said: "philosophy is the father of all human heritages and the distinctive element of science; all philosophers have different opinions leading to reality, different roads to the same goal" (Al-Zajajee, 1959, pp. 46-47).

Al-Zajajee had given us in this chapter a lot of philosophical examples even though his book is about syntax. This matter wouldn't be taken as intervention of human studies but this may be taken as specifying certain philosophy for any part of human studies. Thus, syntax is not excluded because deep grammatical analysis involved linguists with philosophical visions and logical thinking.

\section{Knowledge of Specifying Noun, Verb, and Letter Section}

In specifying noun, Al-Zajajee said "noun in Arabic speech might be subject, object, present participle or past participle. This classification in syntax rules don't get noun out of its natural position as a noun" (Al-Zajajee, 1959, p. 48).

By specifying verb, he clarified that "verb refers to an action in real or unreal time done by a doer or caused by him" (Al-Zajajee, 1959, p. 53). This meant to be that he tried to reach that "verb creates harmony on the structure more than other syntactical parts" (Morgan, 1959, p. 13).

He rejected what Kofian said about the perfect verb when he said "verbs are the dynamic force of the doers and not necessarily their actions but it's some of the things they have mentally or expressed verbally as we said; dynamic force of mind couldn't express two times and this contradicts Kofian when they believed of perfect verb" (Al-Zajajee, 1959, p. 53).

Otherwise, we don't have the same idea with Al-Zajajee dissimilarity with Kofian and his speech of perfect verb because "before the $4^{\text {th }}$ century A.D, the syntactical forms like simple present, present perfect and present continuous weren't used" (Burrow, 1992, p. 45). Today it is possible to construct long texts on the basis of simple verbs. For example, "simple present language functions are facts whether scientific or geographic and expressing habits or a frequent actions in regular durations" (Azar, 1990, p. 11). Thus, the development of language usage correspondent with time variations is a natural matter.

Al-Zajajee had classified alphabets into three kinds: dictionary letters, nouns, verb letters and meaning letters (Al-Zajajee, 1959, p. 54). He agreed that letter affirmation is through noun or verb especially through meaningful sentences when he said: "some linguists said that letters could be affirmed by noun or verb; others said that no meaning could be declared without letters; for examples: "Zaid would not stand", "Baker didn't go out", "your brother is baffled and Mohammad is in the house". The previous examples are just nouns and verbs or two nouns or noun and adverb. These examples describe how letters declare meaning and give an evidence of complete idea for both noun and verb -both depends on each other- despite the fact that this is a description and not a specification for the letter" (Al-Zajajee, 1959, p. 55).

\section{Talking about Verb and Gerund: Which Is Originated from Which}

In this section, Al-Zajajee presents the vision of Al-Basra and Al-Kofah schools about this issue.

For Basrians like Sibawih and others, verbs are taken from gerund but Kofian said that gerund is taken from verb; verb is first, gerund is the second (Al-Zajajee, 1959, p. 56).

Furthermore, Al-Zajajee had mentioned five evidences that Al-Basrians followed to prove their argument:

1) We do fighting, getting out from home and eating before Zaid doing it, then Zaid does all and tells us about it, and so, the fact he does all the previous things, he can't tell us about it, consequently, the gerund that is caused by Zaid preceded by action which means that verb isn't always the first.

2) Masdar ( gerund) in language is the place of the action.

3) If the Masdar (gerund) is often preceded by a verb, it should have an originated verb but not all Masader (gerunds) have preceding verbs depending on Arabic resources like slavery, prophet hood, and mother hood. This will prove that verbs aren't the roots of Masader (gerunds).

4) If Masader (gerunds) or present participles are taken from verbs, we shouldn't see different forms exceeding verbs forms like: drink, do drink, drunk and drinking, or saying: to deviate from reality, do deviate, deviation or deviated from. This means that Masdar (gerund) can freely express meaning without the need of verbs.

5) The evidence that Masdar (gerund) is the origin of the verb is because we can derive the verb from the Masdar (gerund) like saying: went, go, bringing out, to pull out, going out, or saying killed, kill, killer, to kill and 
to defy death, which proves that Masdar (gerund) is there in all Arts as authentic sources of speech (Al-Zajajee, 1959, p. 57-58).

Whereas, Al-Zajajee presents the point of view of Kofians in two evidences:

1) Masdar (gerund) doesn't probably function if the verb isn't meaningfully derived.

2) All Masader (gerunds) could be emphasized by an oral emphasis saying: Zaid was hit "violently" (Al-Zajajee, 1959, p. 60-61).

On the other hand, Al-Zajajee mentioned some problems for those two evidences to deny them when he said: "if I protest to Kofian with this protest -it's not as your scholars said- due to the emphatic name of the Masdar (gerund) like saying: "Zaid was harshly hit".

This example clears up the additional meaning that verb gives its meaning by using the adverb. Moreover, by saying: "Zaid stands up standing" or unnecessary repetition to emphasize the sentence like saying (stand stand, hit hit) which gives stress and emphasis. Therefore, Kofians didn't like the previous examples changing one of the elements on the sentence to be the Masdar (gerund) and not by directly using emphasis and the emphatic for the nouns like saying, "itself" or "himself" or "themselves" (Al-Zajajee, 1959, p. 61).

\section{The Sections of Justifying Problems in Syntax}

Al-Zajajee claimed that the problems of Arabic syntax could be seen in three faces: educational, standard or argumentative theorem. Then, we find him adopting Al-Khalil Ibn Ahmad point of view when he asked about the problems he presented, if he had created it or taken it from Arabic speech? He answered: "that Arab articulated it naturally by knowing its part of speech relying on problematic thinking of them even though they didn't say so; this means; if your sentence carry the meaning, the objectives are carried out. And so, unless there is a problem like saying about the man who entered a well-organized house full of entrances and sections bewildering by the genius of the builder had carried a lot of opinions we couldn't reach" (Al-Zajajee, 1959, pp. 64-66).

\section{The Sections of Structure and Speech: Which One Has Antecedence?}

In this section, there are a lot of negotiations without mentioning names. In this section, Al-Zajajee mostly through that speech has antecedence to structure which proved that the diacritic and the division of parts of speech had appeared lately to remove misunderstanding (Al-Zajajee, 1959, pp. 67-69).

\section{The Sections of Structure; IS IT a Diacritic or an Alphabet?}

Al-Zajajee declared that the Basrians said that the structure is diacritic; "if structure is an alphabet, we can't add another alphabet to it" (Al-Zajajee, 1959, p. 72).

Whereas, the Kofians said structure has both diacritic and alphabet; if it was an alphabet, it would carry the meaning and if it was a diacritic, it wouldn't be meaningful with the alphabet.

Supposedly speaking, Al-Zajajee said that: "Had Sibawih and his students had an answer? If you had roots you would have fixed land, strong syntax even if you are faced with a problem of misunderstanding and this couldn't give an accumulative opinion for this section" (Al-Zajajee, 1959, p. 72).

\section{The Sections about the Antecedents of Verbs}

This is the shortest section, "it is a fact that future is the first head of verbs because it doesn't happen yet carrying in mind that non being is the antecedent of existence, thus non being is the first; then, the present we live in and the past which told us what was happening. The antecedents are; future, present the past" (Al-Zajajee, 1959, p. $85)$.

It's clear that Al-Zajajee had collected philosophy, reason and personal analysis from having a comprehensive look towards the antecedent of "non being" to "existence" to prove a syntactic problem based on sequence of verbs as he found it logically acceptable. This will prove that the syntactic lesson -from his point of view- is not closed to sentences which linguists had dealt with, but it's an open lesson on variety of creative doors of ideas modernization, and creating the newest.

\section{The Section of Genuine for the Aspects of Present Verbs}

In this section, Al-Zajajee clarified the permanent verb problem which Basrians had found it weakness to Kofians: Basrians said that the verb has three sections: present, past and future. Thus, it is impossible to find perfect verb because perfect related to two tenses (Al-Zajajee, 1959, p. 86) which were mentioned before. 
After that, Al-Zajajee started a description about the aspects of the three tenses of verbs; for future verb, this aspect of the supposedly coming time that expresses "non being" rather than expressing "existence" whereas the past verb is what could be expressed about what finished by two tenses not less than that or it had no effect for the present. On the second hand, the present verb is what progressing without interruption starting from the past to reach the beginning of the future due to a long duration of actions. Thus, for this problem sometimes we speak about the future using the present, like when we say "Zaid is going to stand now or is going to stand tomorrow". Or "Abdullah is riding the horse now or is riding his horse tomorrow". And so, if we want to use present for the future we put "s" letter before the present translating "s" to "is going" so we say Zaid is going to stand or Abdullah is going to ride to make its future usage (Al-Zajajee, 1959, p. 87).

\section{The Sections that Talk about Naming this Kind of Speech "Syntax"}

This section is one of the shortest sections too; it takes one page and few lines. We can summarize it by saying that Abu Al-Aswad Al-Doali was the first to be irritated due to poor pronunciation especially that he heard it from his daughter. Therefore, he started composing a book for Arabic main structure but this provoked Zaid Ibn Abiah to stop him for a little time before he gave Abu Al-Aswad the permission due to the increasing of poor pronunciation among people. Abu Al-Aswad lately composed the book, then he ordered the people to use the system of diacritic to make the meaning clear or syntactically correct, and so, it is called the science of syntax calling Abu Al-Aswad the first to write that speech consists of nouns, verbs and prepositions. Thus, when he asked about this he said, I took it from the Caliph Ali Ibn Abu-Taleb (Al-Zajajee, 1959, pp. 89-99).

\section{The Difference between Syntax, Language Structure, Parsing and the Eccentric Section}

In this Section, Al-Zajajee told us that structure is the root of eloquence when he said: "the man declared what he wanted means he made it clear, and man with a good style is the clear eloquence of speech, and also when saying: the widow declares about herself. He added: "when some linguist found diacritic at the end of nouns and verbs to let the word declare about itself, they called this kind of structure good style or eloquence. Otherwise, the Arabic language which was a gift from Allah to Arabs, the oral style of speaking named lingual or glossed, and thus, syntactic diacritic is considered the clarification of language" (Al-Zajajee, 1959, p. 91).

On the other hand, speaking about the uncommon is to speak about the rare usage of some expressions which is rarely used by common people, but the little number of words that are sophisticated are altered like: "I made the man silent" means, "I kick him down" (Al-Zajajee, 1959, p. 92).

\section{The Sections Related to the Significance of the Verb and the Levity of the Noun}

Al-Zajajee summarized some opinions in this section. Basrians said: "the verb has more significance than the nouns. They added that nouns are the first, give more emphatic and nouns replace each other, too. For example, "Allah is our God", "Mohammad is our prophet", "Zaid is your brother"; therefore, we say that verb has no condition or denotation without being related to nouns. Some said the verb always refers to a pre-modifier; thus, we can't ignore the subject while mentioning the verb. Otherwise, some linguists said that the levity of the verb was attributed to the surface meaning and the significance of the verb, object, weather direct or indirect, gerund, the two adverbs of time and place, and the adverbs of manner ... etc. Moreover, scholars like Al-Ksaee, Al-Fraha and Hishman said that: "noun has less weight than verb; noun is defined by verb but verb always the center of the meaning". Another scholar -Thalab- said: nouns have less weight than verbs because nouns are static, verbs are dynamic on the basis of word formation, so verbs are significant (Al-Zajajee, 1959, pp. 100-101).

\section{The Second Chapter: "Syntactical Questions"}

These questions are mentioned under different section titles "a question" for each title without putting a secondary title, giving little space to a question rather than giving a large space to another, starting with two-lined question, three ... etc. until he reaches "12" questions. In these questions, Al-Zajajee didn't pay attention to reasonable arguments or long philosophical speeches but he just went to be brief as in the following questions: "Zaid has been woken up; he woke up suddenly like she - camel, as if he relaxed like the she - camel relaxation as if it has been milked" (Al-Zajajee, 1959, p. 137). About this question, Sibawih said: "if we named this man as red, we didn't put him in the rank of indefinite, but if we named this man as "Yshker" "to thank" we certainly put it in the rank of the definite. Thus, red is rather adjective or noun. He added if the word couldn't be derived, the problem would be in its name but "Byshker" is rather a verb more than being adjective or noun so if "Yoshker" is a name it would be a name due to this significance of the verb. On the other hand, some scholar said that "red" is like "Yshker" could be in the place of noun on the same principle that "Yoshker" is a verb in a place of a noun due to "Yoshker" wouldn't be used as verb (Al-Zajajee, 1959, p. 143). 
At the end of this chapter, a lot of questions are being discussed between language, syntax and meaning.

\section{Epilogue}

In this study, it's clear that modernism isn't monopolized to a certain period of time because we can find varieties of modernism ideas through some articles in the $4^{\text {th }}$ century of Muslim calendar and earlier. Moreover, modernism is not related to a certain type of science or a creative figurative part of speech. Consequently, we can define it as a school in composing books through a creative thinking based on refusing tradition and creating out their own vision.

In his book, The Clarifications in Syntax Justifications, Al-Zajajee didn't try to imitate anyone on writing forms or style because he gave himself the chance to choose the suitable form of writing, style and the argument of the book. Therefore, he wrote several lines calling it a section and sometimes two or few lines calling it "a question".

Al-Zajajee had created his own trend of writing -especially by refusing the view that related to some linguists who look at syntax as a firm science on the basis of structure of the sentence refusing any idea of creativity or modernization-

So, he used personal analysis, discussion, argument, philosophical examples, philosophers, creativity and carving new vision of thinking and style.

It's clear that Al-Zajajee was Basrian on thinking and carving even though he tried -as possible as he could- to be neutral through presenting his point of views, reasoning, giving evidences and individuality.

Moreover, the study had reached that Al-Zajajee is one of the oldest professors who cared a lot about syntactic problems by writing a certain book presenting a lot of problems giving reasonable judgments, logical, and philosophical analysis.

Mentioning the pre-opinions whether he accepts or refuses them or having his individual opinion, thus he always tends to present new ideas on this issue.

His book, The Clarifications in Syntax Justifications has a good classification of subjects, sections and clear in its language, and thought reassuring that Arabic language is a language of a living civilized nation which means it could be developed, living with the new trends of any age in all its aspects: functional, communicational, intellectual, philosophical, reasonable and others.

\section{References}

Abd Al-Hussein Mubarak. (1980). The Biography of Abu Al-Qasem Al-Zajajee. Bagdad: Dar Al-Rasheed for Publishing.

Al-Afghani, S. (1957). In the Origins of Syntax (2nd ed.). Damascus, Syrian University Printing House.

Al-Aqtash Musalam Ismail. (2011). Oral Factors in Arabic Syntax. Amman: Al-Yazoree House for Printing and Editing.

Al-Dainoori, Abu Abdullah Mohammad Ibn Musalam Ibn Qutaibah. (1985). Poetry and Poets; Mofeed Qamiha (3rd ed.). Beirut: Scientific Book House.

Al-Jarjani, Abd Al-Qaher Immutability. (1988). Sings in Arabian Semantics. Beirut: Scientific Book House.

Al-Mubarak, M. (1974). The Syntactic Problems; Origins and Developments. Beirut: Al-Feker House for Printing, Editing and Publishing.

Al-Mubarak, M. (1984). Al-Zajajee: Life, Remaining and Syntactic School Through His Book (2nd ed.). The Clarification, Damascus: Al-Feker House for Printing and Publishing.

Al-Ru'aid, Abd Al-Wakeel Abd Al-Karim. (1987). Diacritic Phenomenon in Arabic Language. Beirut: Al-Nahda Al-Arabia House.

Al-Zajajee, Abu Al-Qasem. (1959). Clarifications in Syntax Justifications. Mazen Al-Mubarak, Cairo: Dar Al-Oroba Library.

Anees, I. (1972). Al-Waseet Dictionary (2nd ed.). Cairo: Arabic Language Semantics Forum.

Azar, B. (1991). Understanding and Using English Grammar (2nd ed.). NewJersy: Prentice Hall Regents.

Burrow, J. A. (1992). A Book of Middle English. Oxford: Blackwell.

Ibn Manthour, Abu Al-Fadel Jamal Al-Deen Mohammad Ibn Mukarram. (1991). The Tongue of Arabs. Beirut: Sader House. 
Makram, Abd Al-Aal Salem. (2012). Holy Quran and its Effects in Syntactic Studies. Cairo: Al-Maaref house.

Morgan, R. B. (1959). A New English Grammar for Junior Forms (5th ed.). London: John Muarry LTD.

\section{Copyrights}

Copyright for this article is retained by the author(s), with first publication rights granted to the journal.

This is an open-access article distributed under the terms and conditions of the Creative Commons Attribution license (http://creativecommons.org/licenses/by/3.0/). 